\title{
Implementing Surviving Sepsis Campaign Guidelines and Mortality of Adult Patients in Intensive Care Units: An Integrative Review
}

\author{
Saleh Al Omar (), Inaam Khalaf, Jafar Alasad Alshraideh \\ School of Nursing, The University of Jordan, Amman, Jordan \\ Email: alomarsaleh@yahoo.com,khalafd@ju.edu.jo,jalasad@ju.edu.jo
}

How to cite this paper: Al Omar, S., Khalaf, I. and Alshraideh, J.A. (2019) Implementing Surviving Sepsis Campaign Guidelines and Mortality of Adult Patients in Intensive Care Units: An Integrative Review. Open Journal of Nursing, 9, 1054-1072. https://doi.org/10.4236/ojn.2019.910078

Received: September 20, 2019

Accepted: October 28, 2019

Published: October 31, 2019

Copyright () 2019 by author(s) and Scientific Research Publishing Inc. This work is licensed under the Creative Commons Attribution International License (CC BY 4.0).

http://creativecommons.org/licenses/by/4.0/

\begin{abstract}
Background: Sepsis is a common dangerous body response to infection that can deteriorate into septic shock. Both sepsis and septic shock require early and timely managed care, which can be implemented by using the Surviving Sepsis Campaign (SSC) guidelines for management of sepsis and septic shock. The purpose of this study was to examine the literature related to the effect of implementing SSC guidelines for management of sepsis and septic shock on adult patients' mortality rate in Intensive Care Units (ICUs). Methods: The method of Whittemore and Knafl was used to guide this integrative literature review. The literature search revealed 16 eligible quantitative research studies between 2004 and 2018. The quality of methods used in the included articles was assessed and data were analyzed. Results: Results showed that implementing SSC guidelines reduced the mortality rate among adult patients in ICUs. In addition, implementing selected practices from SSC guidelines, such as collecting blood cultures and administration of a broad-spectrum antibiotic and vasopressors were found to decrease the mortality rate among adult patients in ICUs. The SSC guidelines need to be taught to nurses and nursing students to increase their awareness and capability of implementing these guidelines in clinical practice.
\end{abstract}

\section{Keywords}

Sepsis, Septic Shock, Mortality, SSC, Guidelines

\section{Introduction}

Sepsis is a life-threatening illness. Every year it affects 30 million people globally [1] and 285 per 100,000 in Taiwan [2]. In Intensive Care Units (ICUs), sepsis 
prevalence ranged from $10.5 \%$ to $37 \%$ in different countries, including France, Germany, the Netherlands, China, and Thailand [2] [3] [4] [5] [6]. In addition, sepsis and septic shock (SS) together were responsible for $25.4 \%$ of ICU admissions during one pilgrim season in Mecca [7].

Sepsis occurs as a dangerous response of the body to infection accompanied by organ dysfunction; it can cause systemic biologic, biochemical, and physiologic abnormalities [8]. Sepsis is characterized by having tachycardia, hypotension, hyperthermia or hypothermia, tachypnea, and leukocytosis or leukopenia. Signs of acute kidney failure, heart failure, and lung dysfunction may start to appear [9]. In cases where sepsis deterioration into SS may occur, patients will have hypotension and poor perfusion, and they will be unresponsive to intravenous fluids administration, making it necessary to administer vasopressors to manage hypotension [8].

Sepsis has negative consequences on health and health-care cost. It was found to be responsible for six million annual deaths around the world, [10] and 250,000 deaths annually in the USA alone [11]. Without proper and systematic management, sepsis can increase the mortality rate, [12] adding an additional \$14 billion dollars to the overall global health expenditure [13]. Moreover, patients with sepsis have been found to have a greater risk of recurrent hospitalization [8] [14] and developing secondary infections later on during hospitalizations, such as pneumonia and bloodstream infections [15]. Fortunately, patients' bad prognosis can be prevented and the mortality rate can be decreased by early management of sepsis and SS [16]. For this reason, nurses must screen patients for sepsis, and sepsis management should be carried out as early as possible when sepsis is suspected [17].

Surviving Sepsis Campaign (SSC) guidelines are intended to provide guidance for the management of sepsis and SS [18]. These guidelines for the management of sepsis and SS were shown to reduce the mortality rate among patients in ICUs, significantly [12] [18] [19]. In Taiwan, Chou et al. (2014) [20] indicated that applying SSC guidelines also decreased the mortality rate from $34.6 \%$ to 24.5\% among patients in ICU. Pestana et al. (2010) [21] conducted a retrospective study. The study results revealed that applying SSC guidelines decreased the mortality rate among 184 patients in ICUs ( $\mathrm{p}<0.001)$.

Nurses have a vital role in screening and early management of sepsis [22]. In Spain, a national educational program for nurses and physicians led to improvement in the care of patients with sepsis, improved compliance with sepsis management, and reduced mortality rate [23]. In addition, a nurse-driven sepsis management protocol can improve compliance with SSC guidelines and enhance early recognition of sepsis [24]. However, many nurses have poorly adhered to guidelines of sepsis diagnoses and management [25]. In any case, sepsis also occurs with other illnesses concurrently, which can be confusing [26].

Searching the different databases, no Integrative Literature Review (ILR) was conducted with the purpose of examining research literature that studied the ef- 
fect of implementing SSC guidelines on adult patients' mortality rate in ICUs. The results of this ILR can help in presenting synthesized evidence, in addition to adding more information to the body of literature about the effect of implementing SSC guidelines on patients' mortality in ICUs. Moreover, having such information can help nurses and other healthcare providers in enhancing management of patients with sepsis and SS. This review will increase awareness of nursing administrators and educators about sepsis management based on SSC guidelines.

\section{Method}

\subsection{Problem Identification}

There are increasing research studies investigating the effect of implementing SSC guidelines for the management of sepsis and SS on adult patients' outcomes. The authors of this ILR identified the need to reach an in-depth understanding of this relationship. The purpose of this ILR was to examine the literature related to the effect of implementing the Surviving Sepsis Campaign (SSC) guidelines for the management of sepsis and SS on adult patients' mortality rate in ICUs.

The proposed method of Whittemore and Knafl (2005) [27] was used to guide this ILR and to improve its rigor. Whittemore and Knafl (2005) [27] modified the integrative literature review method of Cooper (1998) [28], which was composed of five stages: problem formulation; a search of literature; data evaluation; data analysis; and presentation of findings. This updated methodology for ILR enables the rigor to be enhanced. It also enhances data synthesis and combining studies with different methodologies in order to give a wide perspective on phenomena [27]. For the current ILR, this method was beneficial because studies with different methods were included.

\subsection{Literature Search}

The literature search was undertaken in November 2018 by using MEDLINE, Cab Direct, ProQuest Central, SpringerLink, CINAHL Plus, the Cochrane Database of Systematic Reviews, Scopus and Google Scholar. The following keywords were used in different combinations to guide the search: "sepsis", "septic shock", "surviving sepsis campaign", "guidelines", "bundle", "outcomes", "death”, and "mortality". The search was conducted by entering the following words: surviving sepsis campaign AND guidelines AND mortality, surviving sepsis campaign AND guidelines AND death, surviving sepsis campaign AND bundle AND mortality, surviving sepsis campaign AND mortality, sepsis AND bundle AND mortality, septic shock AND bundle AND mortality; surviving sepsis campaign AND septic shock AND mortality. The inclusion criteria for research articles were: 1) Research studies published between 2004 and 2018, because the SSC guidelines for sepsis management were first published in 2004 [29] 2) Studies that investigated the effect of implementing SSC guidelines on adult patients' mortality in ICUs only, with no restriction for study design; 3) Articles written 
in English.

\subsection{Search Results}

The initial search resulted in 729 articles. This search was carried out by the principal investigator. The titles and abstracts were reviewed based on the inclusion criteria to assess articles' eligibility. A total number of 334 research articles were duplicate, they were counted manually by name and frequency, and then duplicates were excluded. An additional 330 articles were excluded based on title and abstract information. The remaining 65 articles were retrieved as full-text and were assessed again for meeting the inclusion criteria; 36 of them were conducted in settings other than ICUs or in mixed settings, and 13 studies were ineligible reviews. Only 16 studies were eligible and the remaining 49 articles were excluded (see Figure 1).

The primary investigator used a research matrix to extract the required data (see Table 1). From each article, the following data were extracted: study purpose, design, settings, sample size, sampling technique, year of implementing the SSC guidelines, and main findings. In addition, the data extracted from the articles were used again to confirm eligibility of the included articles based on the

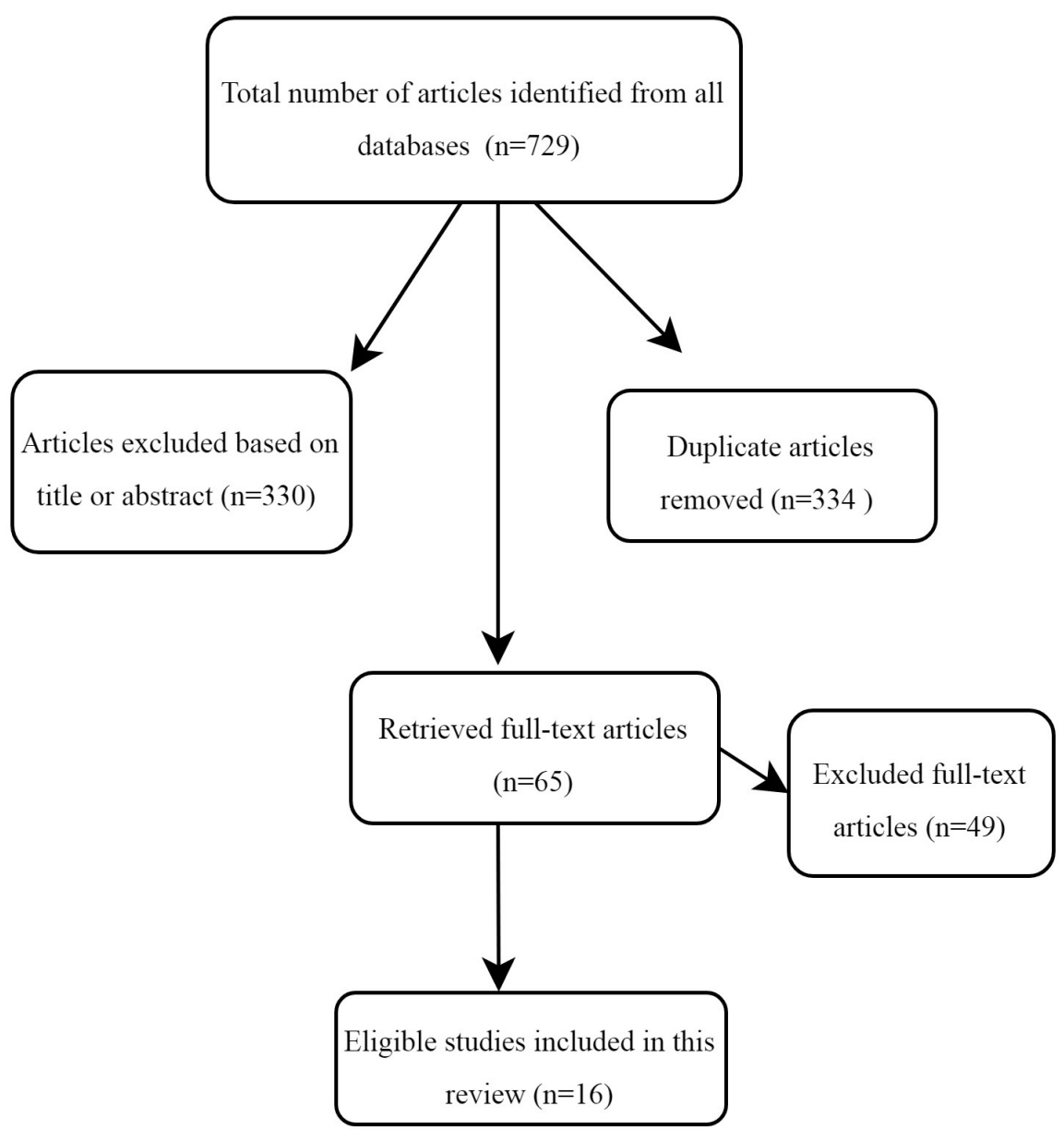

Figure 1. Flow diagram of study selection strategy. 
Table 1. Study characteristics.

\begin{tabular}{|c|c|c|c|c|c|c|}
\hline Authors & Purpose & Design & Settings & $\begin{array}{l}\text { Sample } \\
\text { size and } \\
\text { sampling } \\
\text { technique }\end{array}$ & $\begin{array}{c}\text { Year of } \\
\text { implementing } \\
\text { the SSC } \\
\text { guidelines }\end{array}$ & $\begin{array}{c}\text { Main } \\
\text { findings }\end{array}$ \\
\hline $\begin{array}{l}\text { Chou et al. } \\
(2014)[20]\end{array}$ & $\begin{array}{l}\text { To implement sepsis } \\
\text { guidelines and } \\
\text { examine their effect } \\
\text { on patients with } \\
\text { severe sepsis or } \\
\text { septic shock in ICUs. }\end{array}$ & $\begin{array}{l}\text { A prospective } \\
\text { observational cohort } \\
\text { design. The study had } \\
\text { four phases: } \\
\text { preintervention, } \\
\text { education, operational } \\
\text { and postintervention. }\end{array}$ & $\begin{array}{l}\text { 13-bed ICU in a } \\
\text { tertiary medical } \\
\text { center in south- } \\
\text { ern Taiwan. }\end{array}$ & $\begin{array}{l}\mathrm{N}=164 \\
\text { Convenient }\end{array}$ & 2010 to 2011 & $\begin{array}{l}\text { Implementation } \\
\text { of the modified } \\
\text { sepsis guidelines } \\
\text { was successful in } \\
\text { reduction of } \\
\text { in-hospital } \\
\text { mortality and } \\
\text { hospital } \\
\text { expenditure. } \\
\text { In-hospital } \\
\text { mortality rates } \\
\text { were: } 34.6 \% \\
10.0 \%, 23.1 \% \\
\text { and } 24.5 \% \text {, for } \\
\text { Pre-intervention, } \\
\text { education, } \\
\text { operation and } \\
\text { post-intervention } \\
\text { phases, } \\
\text { respectively } \\
\text { (p }<0.05 \text { ). }\end{array}$ \\
\hline $\begin{array}{l}\text { Pestana et } \\
\text { al. (2010) } \\
{[21]}\end{array}$ & $\begin{array}{l}\text { To analyze the } \\
\text { compliance with a } \\
\text { sepsis guidelines and } \\
\text { the impact of the } \\
\text { fulfillment of } \\
\text { different } \\
\text { therapeutic guide- } \\
\text { lines on ICU survival } \\
\text { in a cohort of surgic- } \\
\text { al patients with sep- } \\
\text { tic shock. }\end{array}$ & $\begin{array}{l}\text { Retrospective, } \\
\text { observational } \\
\text { descriptive design } \\
\text { was used to consider } \\
\text { compliance with } \\
\text { seven quality } \\
\text { indicators of } \\
\text { sepsis bundle. }\end{array}$ & $\begin{array}{l}\text { Surgical } \\
\text { ICUs in two } \\
\text { University } \\
\text { hospitals in Spain. }\end{array}$ & $\begin{array}{l}\mathrm{N}=182 \\
\text { Convenient }\end{array}$ & 2003 and 2008 & $\begin{array}{l}\text { ICU survival } \\
\text { was significantly } \\
\text { related to the } \\
\text { number of } \\
\text { fulfilled } \\
\text { therapeutic } \\
\text { guidelines } \\
\text { included in a } \\
\text { sepsis bundle. } \\
\text { (OR, } 1.64 \text {; } 95 \% \\
\text { CI, } 1.28 \text { - 2.1; } \\
\text { p }<0.001 ; \\
\text { survival was } \\
\text { higher in the } \\
\text { bundle-compliant } \\
\text { patients. } \\
\text { Mortality rates } \\
\text { were } 56.8 \% \text { and } \\
36.8 \% \text { for } \\
\text { patients not } \\
\text { treated by } \\
\text { bundle and } \\
\text { those treated } \\
\text { based on the } \\
\text { bundle, } \\
\text { respectively. }\end{array}$ \\
\hline
\end{tabular}


To describe the effectiveness of the SSC guidelines with regard to both

Castellanos-Ortega et al. (2010) [32]

Patel et al. (2010) [33] To examine the effect of a collaborative 2-part sepsis guidelines on clinical outcomes and mortality at a community hospital.

To determine the rate of compliance with 6-hour and 24-hour sepsis bundles, and

Shiramizo et al. (2011) [34]
A quasi-experimental study that included a post intervention group and a historical comparison group. In addition, educational program based on the SSC guidelines was implemented over a 3 months period.
3 medical-surgical

ICUs in an

academic tertiary care center in Spain.

$\mathrm{N}=384$

Convenient

2005-2008

Quasi-experimental. A multidisciplinary collaborative approach was adopted to conduct the study using retrospective and unblended data collection techniques.

\section{An ICU in a}

non-academic community

\section{hospital}

427-licensed bed for acute care in the USA.

\section{Prospective} quasi-experimental, pre and post design. Bundle compliance and patient outcomes were compared before (July 2005-April 2006) and after (May

2006-December 2009) implementation of the interventions. medical-surgical ICU in a tertiary care private hospital in Sao Paulo, Brazil.
In-hospital mortality was reduced from $57.3 \%$ in the historical group to $37.5 \%$ in the intervention group ( $\mathrm{p}<0.001)$.

The same happened with ICU mortality. The crude difference was (53.1\% vs. $30.5 \%$; $<0.001$ ) Improvements in survival were related to the number of interventions completed ( $\mathrm{p}$ for trend $<0.001)$.

Mortality was $61.1 \%$ in the non-guidelines group versus $20 \%$ with the guidelines $(\mathrm{p}<0.001)$. Implementation of a 2-part sepsis guidelines based on the SSC can yield a positive impact on clinical outcome and mortality.

In-hospital mortality was $54.0 \%$ from July 2005 to April 2006, $41.1 \%$ from May to December 2006, $39.3 \%$ in 2007 ,

$$
\begin{aligned}
& \mathrm{N}=564 \\
& \text { Convenient }
\end{aligned}
$$

2006-2009 $41.4 \%$ in 2008 and $16.2 \%$ in 2009. A statistically significant decreased OR for inpatients mortality was observed when 


\section{Continued}

To evaluate the impact of

Cardoso et compliance with a al. (2010) [35] core version of the SSC 6-hour bundle on 28-day mortality.
Descriptive Cohort, multi-center, prospective study was conducted over one year. Patients were followed up until death or hospital discharge.

$\begin{array}{ll}\text { 17 ICUs in } & \mathrm{N}=778 \\ \text { Portugal. } & \text { Consecutive }\end{array}$

2004 to 2005 there was complete compliance with the 6-hour bundle (OR 0.54; CI 95\% $0.30-0.96, \mathrm{p}=$ 0.033 ) and when there was complete compliance with all of the components of the 24-hour bundle (OR 0.37; CI 95\% $0.24-0.58$, $\mathrm{p}<0.001)$.

Compliance with all actions 1 to 6 was associated with an OR of 0.44 [95\% CI = $0.24-0.80]$ in severe sepsis and 0.49 (95\% CI = $0.25-0.95)$ in septic shock, for 28-days mortality. Collecting blood cultures and giving vasopressors were significantly protective.

The 2011 cohort had a marked reduction in 48-hour (7\% vs $14.8 \%)$, ICU (27.2\% vs $48.2 \%)$, and in-hospital (36.7\% vs $54.3 \%$ ) mortalities.

The implementation of the SSC guidelines resulted in a marked decrease in the overall mortality. 


\begin{tabular}{|c|c|c|c|c|c|c|}
\hline $\begin{array}{l}\text { Lefrant et } \\
\text { al. (2010) } \\
{[37]}\end{array}$ & $\begin{array}{l}\text { To determine } \\
\text { whether the } \\
\text { implementation of } \\
10 \text { recommendations } \\
\text { adapted from the } \\
\text { SSC guidelines } \\
\text { results in a reduction } \\
\text { of mortality } \\
\text { inpatients with } \\
\text { severe sepsis and } \\
\text { septic shock. }\end{array}$ & $\begin{array}{l}\text { Quasi-experimental } \\
\text { study that had two } \\
\text { consecutive phases: a } \\
\text { 6-month quality } \\
\text { control period } \\
\text { (observational) and } \\
\text { secondly a 6-month } \\
\text { intervention period. }\end{array}$ & $\begin{array}{l}15 \text { ICUs in } \\
\text { southern France. }\end{array}$ & $\begin{array}{l}\mathrm{N}=538 \\
\text { Consecutive }\end{array}$ & 2006 & $\begin{array}{l}\text { The } 28 \text {-day } \\
\text { mortality rate } \\
\text { significantly } \\
\text { decreased from } \\
40 \% \text { in the } \\
\text { observational } \\
\text { period to } 27 \% \text { in } \\
\text { the intervention } \\
\text { period }(\mathrm{p}=0.02) \text {. }\end{array}$ \\
\hline $\begin{array}{l}\text { Leisman et } \\
\text { al. (2017) } \\
{[38]}\end{array}$ & $\begin{array}{l}\text { To determine } \\
\text { mortality and costs } \\
\text { associated with } \\
\text { adherence to an } \\
\text { aggressive, 3-hour } \\
\text { sepsis bundle versus } \\
\text { noncompliance } \\
\text { with greater than or } \\
\text { equal to one bundle } \\
\text { element for severe } \\
\text { sepsis and septic } \\
\text { shock patients. }\end{array}$ & $\begin{array}{l}\text { Prospective, multisite, } \\
\text { observational study } \\
\text { used three sequential, } \\
\text { independent cohorts, } \\
\text { from a single USA } \\
\text { health system, } \\
\text { through their } \\
\text { hospitalization. }\end{array}$ & $\begin{array}{l}\text { Three cohorts in } \\
\text { the USA: cohort } \\
\text { 1: five tertiary and } \\
\text { six community } \\
\text { hospitals. Cohort } \\
\text { 2: single tertiary } \\
\text { academic medical } \\
\text { center. Cohort 3: } \\
\text { five tertiary } \\
\text { and four } \\
\text { community } \\
\text { hospitals. }\end{array}$ & $\begin{array}{l}\mathrm{N}=14,755 \\
(\mathrm{n} 1=5819 \\
\mathrm{n} 2=1697 \\
\mathrm{n} 3=7239) \\
\text { Consecutive }\end{array}$ & 2010 & $\begin{array}{l}\text { In the three } \\
\text { independent } \\
\text { cohorts, 3-hour } \\
\text { bundle } \\
\text { compliance was } \\
\text { associated with } \\
\text { improved survival } \\
\text { and cost savings. } \\
\text { Mortality rate for } \\
\text { compliant and } \\
\text { non-compliant } \\
\text { groups were: } \\
21.3 \% \text { and } 25.4 \% \text {, } \\
13.4 \% \text { and } 17.8 \% \\
\text { and } 18.1 \% \text { and } \\
21 \% \text {, for cohorts } \\
1,2 \text { and } 3 \text {, } \\
\text { respectively. }\end{array}$ \\
\hline $\begin{array}{l}\text { Memon et } \\
\text { al. (2012) } \\
{[39]}\end{array}$ & $\begin{array}{l}\text { To assess the effect } \\
\text { of improved } \\
\text { compliance with the } \\
\text { 6-hour sepsis } \\
\text { resuscitation bundle } \\
\text { on mortality of } \\
\text { patients with severe } \\
\text { sepsis and septic } \\
\text { shock. }\end{array}$ & $\begin{array}{l}\text { Quasi-experimental } \\
\text { prospective design } \\
\text { with a historical group } \\
\text { as a control, and an } \\
\text { intervention that was } \\
\text { introduced over a } \\
\text { 3-month period. }\end{array}$ & $\begin{array}{l}\text { 10-bedded } \\
\text { combined } \\
\text { medical and } \\
\text { surgical ICU in a } \\
\text { governmental } \\
\text { hospital in Saudi } \\
\text { Arabia. }\end{array}$ & $\begin{array}{l}\mathrm{N}=299 \\
\text { Consecutive }\end{array}$ & $2009-2011$ & $\begin{array}{l}\text { The overall } \\
\text { compliance with } \\
6 \text {-hour sepsis } \\
\text { resuscitation } \\
\text { bundle elements } \\
\text { was associated } \\
\text { with improved } \\
\text { survival[OR, } 5.8 \\
\text { (95\% CI, } \\
2.2-15.1 \text {; }< \\
0.001)] .30 \text {-day } \\
\text { hospital mortality } \\
\text { reduced from } \\
31.3 \% \text { in the } \\
\text { historical group } \\
\text { to } 21.1 \% \text { in the } \\
\text { intervention } \\
\text { group; } \mathrm{p}=0.05 \text {. } \\
\text { There was a } \\
\text { significant } 30 \text {-day } \\
\text { hospital mortality } \\
\text { reduction in the } \\
\text { post-intervention } \\
\text { group. }\end{array}$ \\
\hline
\end{tabular}




\section{Continued}

To assess the effect on mortality of

Miller III et compliance with a al. (2013)

$[40]$

sepsis and septic

shock management guidelines.

To analyze the evolution of sepsis-related mortality in Spanish

Sánchez et al. (2017)

[41] ICUs following the introduction of the SSC guidelines and the relationship with sepsis process-of-care.

To explore how the level of resuscitation guidelines adherence inhospitals

Thompson [42] influenced changes
An observational retrospective, descriptive design was used. The study was conducted over three stages based on ICU admission date: (1) baseline and bundle development stage, (2) implementation stage, and (3) tracking stage.

Quasi-experimental prospective cohort design was used. The study was conducted during two time periods: 2005 (Edusepsis study pre-intervention group) and 2011 (ABISS-Edusepsis study pre-intervention group).

A quasi-experimental study compared patients with sepsis and septic shock in collaborative hospitals to other groups of patients in

87 Michigan hospitals with in outcomes of patients with sepsis and septic shock.
18 ICUs in 11

hospitals in Utah and Idaho in the USA.

\section{1}

medical-surgical

ICUs in tertiary hospitals in Spain.
$\mathrm{N}=4329$

convenient

2004 and 2010
Severe sepsis and septic shock guidelines were associated with a marked reduction in hospital mortality after adjustment for age, severity of illness, and comorbidities. Relative mortality declined 59.0\% from $21.2 \%$ at baseline to $8.7 \%$ for 2010 ( $\mathrm{p}<$ $0.0001)$.

Patients in the interventional group had lower hospital mortality (32.6\% vs. $44.0 \%$; $\mathrm{p}<0.001)$, lower 28-day mortality (23.0\% vs. $36.5 \%$; $\mathrm{p}<0.001)$, and lower adjusted mortality (OR 0.64 [0.49 - 0.83], $\mathrm{p}=0.001)$.

High adherence hospitals had significantly reduced in-hospital mortality between pre- and post-periods (35.0\% vs $29.7 \%$; $\mathrm{p}<0.001$ ), $\mathrm{N}=48,110$ Convenient 2012-2013 compared to non-collaborative hospitals. High adherence hospitals had significant reductions in mortality (OR, 0.84; 95\% CI, 0.79 - 0.93; $\mathrm{p}<0.001)$. 


$\begin{array}{ll} & \begin{array}{l}\text { To evaluate the effect } \\ \text { of implementation of }\end{array} \\ \text { van Zanten } & \begin{array}{l}\text { SSC bundles on } \\ \text { adherence to the }\end{array} \\ \text { et al. (2014) } & \text { 6- and 24-hour sepsis } \\ {[43]} & \text { bundle targets and } \\ & \text { adjusted in-hospital } \\ \text { mortality. }\end{array}$

Uvizl et al.

(2016) [44]

Ferrer et al. (2009) [45] the diagnosis of severe sepsis/septic shock.
Quasi-experimental, prospective, multicenter cohort in participating and nonparticipating centers.
82 ICUs in the Netherlands.

$\mathrm{N}=16,418$

Convenient

2009-2013

17 ICUs with a total of 220 beds in 12 hospitals in the Czech Republic.

$$
\mathrm{N}=1082
$$
Consecutive

2011-2013 aged 18 and over who were admitted to participating ICUs from 1 January 2011 to 5 November 2013.
Prospective, observational descriptive study that included three inclusion periods: a 2-month period before the implementation of an educational program, a 4-month period after its implementation, and a 2-month, long-term follow-up for 1 year.
Adherence to sepsis bundles was associated with reduced adjusted in-hospital mortality only in participating ICUs, adjusted OR per month = 0.992 [0.986 $0.997]$ ) equivalent to $5.8 \%$ adjusted absolute mortality reduction over 3.5 years. A relative in-hospital mortality reduced by $16.7 \%$ over 3.5 years among patients in the ICUs.

The most effective measures associated with the lowest in-hospital mortality in patients with septic shock were CVP of $\geq 8-12$ $\mathrm{mm} \mathrm{Hg}$, MAP of $\geq 65 \mathrm{~mm} \mathrm{Hg}$, urine output at $\geq 0.5 \mathrm{~mL} / \mathrm{kg} / \mathrm{h}$, initial lactate level of $\leq 4.0 \mathrm{mmol} / \mathrm{L}$ and administration of antibiotics within the first hour.

Early administration of broad-spectrum antibiotics in all patients reduce mortality.

Abbreviations: SSC: Surviving Sepsis Campaign; ICU: Intensive Care Unit; P: Power level or $\alpha$; OR: Odd Ratio; CI: Confidence Interval; USA: United States of America; CVP: Central Venous Pressure; MAP: Mean Arterial Pressure; N: total sample size; n: sample size of a particular group; ScvO2: Central venous oxygen saturation; mm: millimol; ml: millileter; kg: Kiogram; h: hour; mmol: millimol; L: liter; mmHg: millimetre of mercury. 
discussed eligibility criteria. Furthermore, the quality of the extracted data was checked by the second investigator by reading all of the 16 eligible articles and confirming the data of the research matrix. All of the 16 eligible articles are quantitative. Five of them were conducted in Spain, four studies were conducted in the USA, and the remaining seven studies were conducted in Portugal, France, Brazil, Saudi Arabia, Taiwan, the Netherlands, and the Czech Republic, with one study for each of the mentioned countries.

\subsection{Data Evaluation, Rigor and Data Quality}

The quality of methods used in the included articles was assessed by using criteria for assessing the quality of quantitative studies, which was recommended by Kmet et al. (2014) [30]. The criteria have 14 domains, for which the answers and scoring can be as follows: (Yes $=2)$; (Partially $=1) ;(\mathrm{No}=0)$; and not applicable. The quality score of each article was calculated by summing the total score of items and dividing it by the highest possible total score after removing non-applicable items [30]. The calculated summary score for each article can range between zero and two (see Table 2). This assessment was confirmed by the two other researchers.

\subsection{Data Analysis}

Based on Whittemore and Knafl's (2005) [27] method of ILR, analysis has four phases: 1) Data reduction: classifying and dividing data into subgroups; 2) Data display: showing data as they appeared in the research matrix (data extraction sheet), in order to enhance comparison; 3) Data comparison: examining data to identify pattern, relationships, and themes, by which variables can be grouped together and a conceptual map can be drawn; 4) Conclusion drawing and verification: by collecting the different parts that make up the whole general picture and verifying them, followed by synthesizing data and data integration. However, in order to use a more rigorous and well-described process of data analysis, inductive content analysis was used in addition to step number three above, as described by Elo and Kyngäs (2008) [31]. This included: coding, categorizing, collecting categories into higher order headings to decrease the number of headings, and finally abstracting by making a general description of the findings.

\section{Results}

The reviewed articles revealed that implementing SSC guidelines can reduce mortality rate among adult patients in ICUs [20] [21] [32]-[43]. It was shown that implementing the SSC guidelines reduced the mortality rate among adult patients in ICU from $54.0 \%$ to $16.2 \%(\mathrm{~N}=564)$ [34], from $35.0 \%$ to $29.7 \%(\mathrm{p}<$ $0.001)(\mathrm{N}=48110)$ [42], and from $56.8 \%$ to $36.8 \%$ [21]. In addition, implementing the SSC guidelines was associated with improved patient survival [odds ratio (OR), $5.8(95 \%$ CI, $2.2-15.1 ; \mathrm{p}<0.001)$ ] [39] with relative mortality rate declined from $21.2 \%$ to $8.7 \%(\mathrm{p}<0.0001)[40]$. 
Table 2. Quality and rigor of the eligible studies.

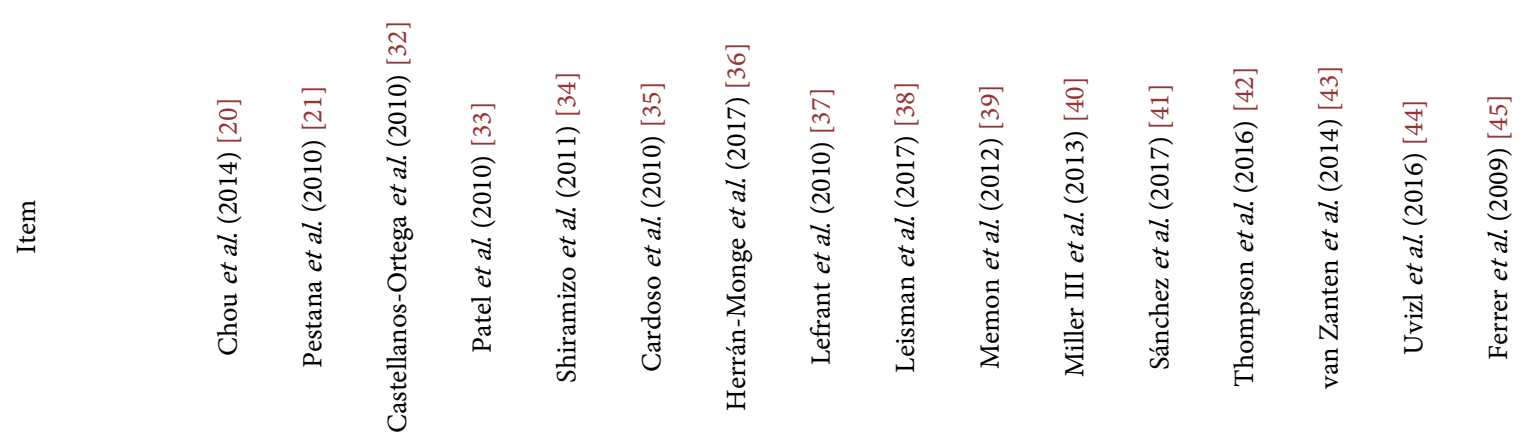

Question/objective sufficiently described?

Study design evident and appropriate?

Method of subject/comparison group selection or source of information/input variables described and appropriate?

Subject (and comparison group, if applicable) characteristics sufficiently described?

If interventional and random allocation was possible, NA NA NA NA NA NA NA NA NA

was it described?

If interventional and blinding of investigators was possible, was it reported?

If interventional and blinding of subjects was possible,

Outcome and (if applicable) exposure measure(s) well defined and robust to measurement/misclassify cation bias? Means of assessment reported?

Sample size appropriate?

Analytic methods described/justified and appropriate? 


\section{Continued}

\begin{tabular}{|c|c|c|c|c|c|c|c|c|c|c|c|c|c|c|c|c|}
\hline $\begin{array}{l}\text { Some estimate of variance } \\
\text { is reported for the main } \\
\text { results? }\end{array}$ & 1 & 2 & 1 & 2 & 2 & 2 & 2 & 2 & 2 & 1 & 2 & 1 & 2 & 0 & 2 & 2 \\
\hline $\begin{array}{l}\text { Controlled for } \\
\text { confounding? }\end{array}$ & 0 & 0 & 0 & 0 & 1 & 1 & 1 & 1 & 0 & 0 & 0 & 1 & 0 & 1 & 1 & 0 \\
\hline $\begin{array}{l}\text { Results reported in } \\
\text { sufficient detail? }\end{array}$ & 2 & 2 & 1 & 2 & 2 & 2 & 1 & 2 & 2 & 1 & 2 & 2 & 2 & 2 & 2 & 2 \\
\hline $\begin{array}{l}\text { Conclusions supported by } \\
\text { the results? }\end{array}$ & 2 & 2 & 2 & 2 & 2 & 2 & 2 & 2 & 2 & 2 & 2 & 2 & 2 & 2 & 2 & 2 \\
\hline Summary Score & 0.60 & 0.68 & 0.73 & 0.64 & 0.77 & 0.77 & 0.68 & 0.68 & 0.71 & 0.60 & 0.68 & 0.86 & 0.86 & 0.73 & 0.77 & 0.77 \\
\hline
\end{tabular}

\subsection{SSC Guidelines and In-Hospital Mortality}

Implementing SSC guidelines were found to reduce in-hospital mortality rates [20] [40] [41] [42] [43]. Specifically, in-hospital mortality was reduced from $57.3 \%$ to $37.5 \%(\mathrm{p}<0.001)(\mathrm{N}=384)[32]$, from $44.0 \%$ to $32.6 \%(\mathrm{p}<0.001)(\mathrm{N}=$ 1348) [41], from $61.1 \%$ to $20 \%(\mathrm{p}<0.001)(\mathrm{N}=112)$ [33], 35.0\% to $29.7 \%(\mathrm{p}<$ 0.001 ) [42], and from $54.3 \%$ to $36.7 \%$ [36]. Furthermore, in-hospital mortality was reduced in ICUs by $5.8 \%$ over 3.5 years, with a relative in-hospital mortality reduction of $16.7 \%$ among adult patients with sepsis and SS in ICUs compared to baseline [43].

\subsection{SSC Guidelines, 28-Day Mortality, 30-Day Mortality, and ICU Mortality}

Implementing SSC guidelines reduced 28-day mortality among adult patients in ICUs [35] [37] [41], from $40 \%$ to $27 \%(\mathrm{p}=0.02)(\mathrm{N}=538)$ [37], and from $36.5 \%$ to $23.0 \%(\mathrm{p}<0.001)(\mathrm{N}=1384)$ [41], with odds ratio $(\mathrm{OR})$ of 0.44 [95\% confidence interval $(\mathrm{CI})=0.24-0.80]$ in sepsis and $0.49(95 \% \mathrm{CI}=0.25-0.95)$ for association of implementing the SSC guidelines with 28-day mortality [35]. Similarly, 30-day mortality was reduced from $31.3 \%$ to $21.1 \%(\mathrm{p}=0.05)$ [39]. In addition, implementing the SSC guidelines reduced ICU mortality rates [21] [32] [36], from $48.2 \%$ to $27.2 \%$ ( $p<0.01$ ) [36], from $53.1 \%$ to $30.5 \%$ ( $p<0.001$ ) [32], and from $56.8 \%$ to $36.8 \%(\mathrm{p}=0.036)$ [21].

\subsection{Certain Selected Guidelines and Patient Mortality}

Two studies investigated the effect of implementing certain practices selected from the SSC guidelines, such as the administration of antibiotics, which was found to decrease the mortality rate [44] [45]. Specifically, the risk of mortality in the case of administering a broad-spectrum antibiotic during the first hour of sepsis compared with no antibiotic in the first 6 hours had an odds ratio [OR] of 0.67; 95\% confidence interval [CI], $0.50-0.90 ; \mathrm{p}<0.01$ ) [45]. In addition, collecting blood cultures and giving vasopressors decreased the mortality rate among adult patients with sepsis and septic shock in ICUs [35]. Castellanos- 
Ortega et al. (2010) [32] pointed out that an inverse relationship exists between mortality rate and the number of implemented SSC guidelines for the management of septic shock. In more detail, the mortality rate was significantly related to the number of accomplished therapeutic guidelines, with an odds ratio [OR] of $1.64 ; 95 \%$ confidence interval [CI], $1.28-2.1$ ( $\mathrm{p}<0.001)$ [21].

\section{Discussion}

Common themes that emerged from this ILR were: First, implementing the SSC guidelines can decrease the mortality rate among adult patients with sepsis and SS in ICUs; this corresponds to the findings of Lefrant et al. [37], Leisman et al. [38], Patel et al. [33], Pestana et al. [21], Cardoso et al. [35], Memon et al. [39], Sánchez et al. [41], Thompson et al. [42], van Zanten et al. [43], and Levy et al. [12]. The second emerged theme was that implementing certain selected guidelines, such as collecting blood cultures and administering broad-spectrum antibiotics and vasopressors can also reduce the mortality rate among adult ICU patients, which was consistent with the findings of Uvizl et al. [44] and Ferrer et al. [45]. The calculated scores for rigor of the research articles ranged between 0.60 and 0.86 , with a mean average of $0.72 \pm 0.078$. The distribution of scores on histogram was close to normal distribution with skewness level of 0.26 . A cut-point score of 0.75 is conservative, while a cut-point score of 0.55 is liberal [30]. However, the minimum score of the included studies was 0.60 indicating adequate rigor of the included studies; therefore, no studies were excluded based on the calculated scores.

There are some limitations of the reviewed studies. Out of the 16 eligible articles, six research articles were descriptive in nature, while the remaining ten research articles used a quasi-experimental design. However, for the discussed clinical problem, quantitative studies are the type of study expected to investigate the research problem in a suitable way. However, the sample size was small in the observational study of Pestana et al. [21], which may limit its generalizability. The studies of van Zanten et al. [43], Thompson et al. [42], Uvizl et al. [44], Sánchez et al. [41], and Leisman et al. [38], recruited large numbers of participants. Moreover, the studies of Ferrer et al. [45], Castellanos-Ortega et al. [32], Patel et al. [33], Shiramizo et al. [34], Thompson et al. [42], Chou et al. [20], and Herrán-Monge et al. [36] used convenient samples of patients, which might have carried a risk of sampling bias [46]. Furthermore, the studies of Pestana et al. [21], Miller III et al. [40], and Uvizl et al. [44] used a retrospective observational research design, which might not be a robust design to be used for answering such research question.

Some possible confounding variables were not controlled in some studies. For example, the variable of baseline severity of patients' illness was not measured in the study by Thompson et al. [42]. In addition, around half of the included patients in the study by Pestana et al. [21] were patients with cancer, which might limit the generalizability of the study. The reviewed studies came from a wide 
variety of countries where healthcare and implementation practices likely differ, and the populations were different also. In addition, the implemented guidelines were belonging to the period between 2004 and 2013, which indicate different updates of the guidelines. These differences might explain some of the variability in the results.

\section{Conclusions}

The reviewed articles revealed that implementing SSC guidelines for adult patients with sepsis and SS in ICUs has decreased mortality rates. The findings of the current ILR imply that nurses and physicians working in multidisciplinary teams at ICUs are required to implement the guidelines of SSC while providing care for adult patients with sepsis and SS. Educational campaigns and continuous learning programs are needed to teach nurses about the importance of implementing the SSC guidelines and how to implement them. Moreover, internal audit teams can be formed to evaluate nurses' compliance with the SSC guidelines for managing patients with sepsis and SS in ICUs. Furthermore, the SSC guidelines need to be taught to nursing students to increase their awareness and capability of implementing these guidelines in clinical practice.

All of the eligible studies included in the current ILR were conducted between 2004 and 2013, so studying the effect of implementing the newly released guidelines of SSC 2016 and 2018 for the management of sepsis and SS on adult patients' mortality is recommended. The findings of this ILR need to be considered by administrators and policymakers in order to integrate the SSC guidelines of sepsis management during providing care for patients in ICUs. Future studies that may seek to investigate the same problem need to take into consideration using more rigorous research designs, such as the use of randomized allocation of participants and blinding techniques.

\section{Conflicts of Interest}

The authors declare no conflicts of interest regarding the publication of this paper.

\section{References}

[1] World Health Organization (WHO) (2018) Sepsis. https://www.who.int/news-room/fact-sheets/detail/sepsis

[2] Shen, H.N., Lu, C.L. and Yang, H.H. (2010) Epidemiologic Trend of Severe Sepsis in Taiwan from 1997 through 2006. Chest, 138, 298-304. https://doi.org/10.1378/chest.09-2205

[3] van Gestel, A., Bakker, J., Veraart, C.P. and van Hout, B.A. (2004) Prevalence and Incidence of Severe Sepsis in Dutch Intensive Care Units. Critical Care, 8, R153. https://doi.org/10.1186/cc2858

[4] Zhou, J., Qian, C., Zhao, M., Yu, X., Kang, Y., Ma, X., Wu, D., et al. (2014) Epidemiology and Outcome of Severe Sepsis and Septic Shock in Intensive Care Units in Mainland China. PLoS ONE, 9, e107181. 
https://doi.org/10.1371/journal.pone.0107181

[5] Blanco, J., Muriel-Bombín, A., Sagredo, V., Taboada, F., Gandía, F., Tamayo, L., De Frutos, M., et al. (2008) Incidence, Organ Dysfunction and Mortality in Severe Sepsis: A Spanish Multicentre Study. Critical Care, 12, R158.

https://doi.org/10.1186/cc7157

[6] Quenot, J.P., Binquet, C., Kara, F., Martinet, O., Ganster, F., Navellou, J.C. and Perez, P. (2013) The Epidemiology of Septic Shock in French Intensive Care Units: The Prospective Multicenter Cohort EPISS study. Critical Care, 17, R65. https://doi.org/10.1186/cc12598

[7] Baharoon, S., Al-Jahdali, H., Al Hashmi, J., Memish, Z.A. and Ahmed, Q.A. (2009) Severe Sepsis and Septic Shock at the Hajj: Etiologies and Outcomes. Travel Medicine and Infectious Disease, 7, 247-252. https://doi.org/10.1016/j.tmaid.2008.09.002

[8] Neviere, R. (2018) Sepsis Syndromes in Adults: Epidemiology, Definitions, Clinical Presentation, Diagnosis, and Prognosis. UpToDate.

https://www.uptodate.com/contents/sepsis-syndromes-in-adults-epidemiology-defi nitions-clinical-presentation-diagnosis-and-prognosis

[9] De Backer, D., Creteur, J., Preiser, J.C., Dubois, M.J. and Vincent, J.L. (2002) Microvascular Blood Flow Is Altered in Patients with Sepsis. American Journal of Respiratory and Critical Care Medicine, 166, 98-104. https://doi.org/10.1164/rccm.200109-016OC

[10] Fleischmann, C., Scherag, A., Adhikari, N.K., Hartog, C.S., Tsaganos, T., Schlattmann, P., Reinhart, K., et al. (2016) Assessment of Global Incidence and Mortality of Hospital-treated Sepsis. Current Estimates and Limitations. American Journal of Respiratory and Critical Care Medicine, 193, 259-272. https://doi.org/10.1164/rccm.201504-0781OC

[11] Centers for Disease Control and Prevention (CDC) (2016) Data and Reports, Sepsis. https://www.cdc.gov/sepsis/datareports/index.html

[12] Levy, M.M., Dellinger, R.P., Townsend, S.R., Linde-Zwirble, W.T., Marshall, J.C., Bion, J., Parker, M.M., et al. (2010) The Surviving Sepsis Campaign: Results of an International Guideline-based Performance Improvement Program Targeting Severe Sepsis. Intensive Care Medicine, 36, 222-231. https://doi.org/10.1007/s00134-009-1738-3

[13] Picard, K.M., O’Donoghue, S.C., Young-Kershaw, D.A. and Russell, K.J. (2006) Development and Implementation of a Multidisciplinary Sepsis Protocol. Critical Care Nurse, 26, 43-54.

[14] Ortego, A., Gaieski, D.F., Fuchs, B.D., Jones, T., Halpern, S.D., Small, D.S., Mikkelsen, M.E., et al. (2015) Hospital-Based Acute Care Use in Survivors of Septic Shock. Critical Care Medicine, 43, 729-737. https://doi.org/10.1097/CCM.0000000000000693

[15] van Vught, L.A., Klouwenberg, P.M.K., Spitoni, C., Scicluna, B.P., Wiewel, M.A., Horn, J., van der Poll, T., et al. (2016) Incidence, Risk Factors, and Attributable Mortality of Secondary Infections in the Intensive Care Unit after Admission for Sepsis. The Journal of the American Medical Association, 315, 1469-1479. https://doi.org/10.1001/jama.2016.2691

[16] Nelson, D.P., LeMaster, T.H., Plost, G.N. and Zahner, M.L. (2009) Recognizing Sepsis in the Adult Patient. The American Journal of Nursing, 109, 40-45. https://doi.org/10.1097/01.NAJ.0000346928.90369.10

[17] Robson, W., Beavis, S. and Spittle, N. (2007) An Audit of Ward Nurses' Knowledge of Sepsis. Nursing in Critical Care, 12, 86-92. 
https://doi.org/10.1111/j.1478-5153.2007.00210.x

[18] Dellinger, R., Levy, M., Rhodes, A., et al. (2013) Surviving Sepsis Campaign: International Guidelines for Management of Severe Sepsis and Shock: 2012. Critical Care Medicine, 41, 580-637.

[19] Giuliano, K.K., Lecardo, M. and Staul, L. (2011) Impact of Protocol Watch on Compliance with the Surviving Sepsis Campaign. American Journal of Critical Care, 20, 313-321. https://doi.org/10.4037/ajcc2011421

[20] Chou, S.L., Chan, K.S., Cheng, K.C., Chou, W., Hung, H.M. and Chen, C.M. (2014) The Implementation of Sepsis Bundles on the Outcome of Patients with Severe Sepsis or Septic Shock in Intensive Care Units. International Journal of Gerontology, 8 , 60-65. https://doi.org/10.1016/j.ijge.2013.01.016

[21] Pestaña, D., Espinosa, E., Sangüesa-Molina, J.R., Ramos, R., Pérez-Fernández, E., Duque, M. and from the REASEP Sepsis Study Group (2010) Compliance with a Sepsis Bundle and Its Effect on Intensive Care Unit Mortality in Surgical Septic Shock Patients. Journal of Trauma and Acute Care Surgery, 69, 1282-1287. https://doi.org/10.1097/TA.0b013e3181c4539f

[22] Burney, M., Underwood, J., McEvoy, S., Nelson, G., Dzierba, A., Kauari, V. and Chong, D. (2012) Early Detection and Treatment of Severe Sepsis in the Emergency Department: Identifying Barriers to Implementation of a Protocol-Based Approach. Journal of Emergency Nursing, 38, 512-517. https://doi.org/10.1016/j.jen.2011.08.011

[23] Ferrer, R., Artigas, A., Levy, M.M., Blanco, J., Gonzalez-Diaz, G., Garnacho-Montero, J. and Edusepsis Study Group (2008) Improvement in Process of Care and Outcome after a Multicenter Severe Sepsis Educational Program in Spain. The Journal of the American Medical Association, 299, 2294-2303. https://doi.org/10.1001/jama.299.19.2294

[24] Tromp, M., Hulscher, M., Bleeker-Rovers, C.P., Peters, L., van den Berg, D.T., Borm, G.F., Pickkers, P., et al. (2010) The Role of Nurses in the Recognition and Treatment of Patients with Sepsis in the Emergency Department: A Prospective Before-and-after Intervention Study. International Journal of Nursing Studies, 47, 1464-1473. https://doi.org/10.1016/j.ijnurstu.2010.04.007

[25] Stamataki, P., Papazafiropoulou, A., Kalaitzi, S., Sarafis, P., Kagialari, M., Adamou, E. and Hellenic Sepsis Study Group (2014) Knowledge Regarding Assessment of Sepsis Among Greek Nurses. Journal of Infection Prevention, 15, 58-63. https://doi.org/10.1177/1757177413513816

[26] Gaieski, E., Edwards, J., Kalian, M. and Carr, B. (2013) Benchmarking the Incidence and Morality of Severe Sepsis in the United States. Critical Care Medicine, 41, 1167-1174. https://doi.org/10.1097/CCM.0b013e31827c09f8

[27] Whittemore, R. and Knafl, K. (2005) The Integrative Review: Updated Methodology. Journal of Advanced Nursing, 52, 546-553. https://doi.org/10.1111/j.1365-2648.2005.03621.x

[28] Cooper, H.M. (1998) Synthesizing Research: A Guide for Literature Reviews. 2nd Edition, Sage, Thousand Oaks, CA.

[29] Perman, S.M., Goyal, M. and Gaieski, D.F. (2012) Initial Emergency Department Diagnosis and Management of Adult Patients with Severe Sepsis and Septic Shock. Scandinavian Journal of Trauma, Resuscitation and Emergency Medicine, 20, 41. https://doi.org/10.1186/1757-7241-20-41

[30] Kmet, L.M., Cook, L.S. and Lee, R.C. (2014) Standard Quality Assessment Criteria for Evaluating Primary Research Papers from a Variety of Fields. Edmonton: Al- 
berta Heritage Foundation for Medical Research (AHFMR).

https://www.ihe.ca/publications/standard-quality-assessment-criteria-for-evaluating -primary-research-papers-from-a-variety-of-fields

[31] Elo, S. and Kyngäs, H. (2008) The Qualitative Content Analysis Process. Journal of Advanced Nursing, 62, 107-115. https://doi.org/10.1111/j.1365-2648.2007.04569.x

[32] Castellanos-Ortega, Á., et al. (2010) Impact of the Surviving Sepsis Campaign Protocols on Hospital Length of Stay and Mortality in Septic Shock Patients: Results of a Three-Year Follow-up Quasi-experimental Study. Critical Care Medicine, 38, 1036-1043. https://doi.org/10.1097/CCM.0b013e3181d455b6

[33] Patel, G.W., Roderman, N., Gehring, H., Saad, J. and Bartek, W. (2010) Assessing the Effect of the Surviving Sepsis Campaign Treatment Guidelines on Clinical Outcomes in a Community Hospital. Annals of Pharmacotherapy, 44, 1733-1738. https://doi.org/10.1345/aph.1P251

[34] Shiramizo, S.C.P.L., Marra, A.R., Durão, M.S., Paes, Â.T., Edmond, M.B. and dos Santos, O. (2011) Decreasing Mortality in Severe Sepsis and Septic Shock Patients by Implementing a Sepsis Bundle in a Hospital Setting. PLoS ONE, 6, e26790. https://doi.org/10.1371/journal.pone.0026790

[35] Cardoso, T., Carneiro, A.H., Ribeiro, O., Teixeira-Pinto, A. and Costa-Pereira, A. (2010) Reducing Mortality in Severe Sepsis With the Implementation of a Core 6-Hour Bundle: Results from the Portuguese Community-Acquired Sepsis Study (SACiUCI study). Critical Care, 14, R83. https://doi.org/10.1186/cc9008

[36] Herrán-Monge, R., Muriel-Bombín, A., García-García, M.M., Merino-García, P.A., Martínez-Barrios, M., Andaluz, D., Álvarez-Martínez, B., et al. (2017) Epidemiology and Changes in Mortality of Sepsis after the Implementation of Surviving Sepsis Campaign Guidelines. Journal of Intensive Care Medicine, 34, 740-750. https://doi.org/10.1177/0885066617711882

[37] Lefrant, J.Y., Muller, L., Raillard, A., Jung, B., Beaudroit, L., Favier, L., Jonquet, O., et al. (2010) Reduction of the Severe Sepsis or Septic Shock Associated Mortality by Reinforcement of the Recommendations Bundle: A Multicenter Study. Annales Francaises D'anesthesie et de Reanimation, 29, 621-628.

https://doi.org/10.1016/j.annfar.2010.04.007

[38] Leisman, D.E., Doerfler, M.E., Ward, M.F., Masick, K.D., Wie, B.J., Gribben, J.L., D’Angelo, J.K., et al. (2017) Survival Benefit and Cost Savings from Compliance with a Simplified 3-Hour Sepsis Bundle in a Series of Prospective, Multisite, Observational Cohorts. Critical Care Medicine, 45, 395-406. https://doi.org/10.1097/CCM.0000000000002184

[39] Memon, J.I., Rehmani, R.S., Alaithan, A.M., El Gammal, A., Lone, T.M., Ghorab, K. and Abdulbasir, A. (2012) Impact of 6-Hour Sepsis Resuscitation Bundle Compliance on Hospital Mortality in a Saudi Hospital. Critical Care Research and Practice, 2012, 273268. https://doi.org/10.1155/2012/273268

[40] Miller, R.R., Dong, L., Nelson, N.C., Brown, S.M., Kuttler, K.G., Probst, D. R. and Intermountain Healthcare Intensive Medicine Clinical Program (2013) Multicenter Implementation of a Severe Sepsis and Septic Shock Treatment Bundle. American Journal of Respiratory and Critical Care Medicine, 188, 77-82. https://doi.org/10.1164/rccm.201212-2199OC

[41] Sánchez, B., Ferrer, R., Suarez, D., Romay, E., Piacentini, E., Gomà, G. and Edusepsis Study Group (2017) Declining Mortality Due to Severe Sepsis and Septic Shock in Spanish Intensive Care Units: A Two-Cohort Study in 2005 and 2011. Medicina Intensiva, 41, 28-37. https://doi.org/10.1016/j.medin.2016.09.004 
[42] Thompson, M.P., Reeves, M.J., Bogan, B.L., DiGiovine, B., Posa, P.J. and Watson, S.R. (2016) Protocol-Based Resuscitation Bundle to Improve Outcomes in Septic Shock Patients: Evaluation of the Michigan Health and Hospital Association Keystone Sepsis Collaborative. Critical Care Medicine, 44, 2123-2130. https://doi.org/10.1097/CCM.0000000000001867

[43] van Zanten, A.R., Brinkman, S., Arbous, M.S., Abu-Hanna, A., Levy, M.M. and de Keizer, N.F. (2014) Guideline Bundles Adherence and Mortality in Severe Sepsis and Septic Shock. Critical Care Medicine, 42, 1890-1898. https://doi.org/10.1097/CCM.0000000000000297

[44] Uvizl, R., Adamus, M., Cerny, V., Dusek, L., Jarkovsky, J., Sramek, V. and Sevcik, P. (2016) Patient Survival, Predictive Factors and Disease Course of Severe Sepsis in Czech Intensive Care Units: A Multicentre, Retrospective, Observational study. Biomedical Papers of the Medical Faculty of Palacky University in Olomouc, 160, 287-97. https://doi.org/10.5507/bp.2015.052

[45] Ferrer, R., Artigas, A., Suarez, D., Palencia, E., Levy, M.M., Arenzana, A., Sirvent, J.M., et al. (2009) Effectiveness of Treatments for Severe Sepsis: A Prospective, Multicenter, Observational Study. American Journal of Respiratory and Critical Care Medicine, 180, 861-866. https://doi.org/10.1164/rccm.200812-1912OC

[46] Polit, D. and Beck, C. (2015). Nursing Research: Generating and Assessing Evidence for Nursing Practice. 10th Edition, Lippincott Williams and Wilkins, Philadelphia, PA. 